\title{
БРЕКЗИТ: ВТОРОЙ РЕФЕРЕНДУМ?
}

Аннотация. Осознав, что Соглашение о выходе Британии из Европейского Союза не получит одобрение депутатов, премьер-министр Британии Т. Мэй отложила голосование по «сделке». Вотум доверия фракиии консерваторов своему лидеру не изменил расклад сил в Вестминстере: среди депутатов не сложилось большинство ни по одному из вариантов брекзита. Британцы недовольны соглашением, но и среди них нет единства относительно отношений с ЕС. В обществе муссируется идея второго референдума как выхода из тупика. Возможен ли новый референдум?

Ключевые слова: брекзит, Тереза Мэй, Соглашение о выходе Британии из ЕС, британский парламент, Европейский союз.

\section{Может ли Британия остаться в Европейском Союзе?}

10 декабря 2018 г. Суд ЕС постановил, что Лондон может в одностороннем порядке отменить выход из ЕС (не испрашивая согласие 27 других стран-членов), отозвав уведомление о намерении выйти из Евросоюза (согласно ст. 50 Лиссабонского договора) ${ }^{1}$. Выход из международного договора может быть отозван до вступления международного договора в действие на основании суверенного права государства. Постановление Суда ЕС стало ответом на ходатайство группы шотландских политиков - депутатов Холируда, Вестминстера и Европарламента. Тем самым Британия получает возможность «передумать», но правительство постоянно заявляло, что не станет отзывать своё уведомление 2 . Постановление вызвало восторг бремейнеров, которые рассчитывают на второй референдум с положительным исходом - сохранение членства Британии в ЕС.

\section{Дебаты в парламенте}

Между тем в Палате общин прошли пятидневные дебаты по Соглашению Британии с ЕС и Политической декларации ${ }^{3}$ в преддверии голосования 11 декабря. Перед летними кани-

\footnotetext{
(C) Ананьева Елена Владимировна - кандидат философских наук, ведущий научный сотрудник, руководитель Центра британских исследований ИЕ РАН. Адрес: 125009, Россия, Москва, ул. Моховая, д. 11, стр. 3. E-mail: e-ananieva@yandex.ru.
}

DOI: http://dx.doi.org/10.15211/vestnikieran6201810

${ }^{1}$ Court of Justice of the European Union. PRESS RELEASE No 191/18. URL: https://curia.europa.eu/jcms/ upload/docs/application/pdf/2018-12/cp180191en.pdf (дата обращения: 10 декабря 2018 г.).

${ }^{2}$ BREXIT LIVE: May faces FRESH DISASTER as Government accused of committing CONTEMPT. URL: https:// www.express.co.uk/news/politics/1053507/brexit-live-theresa-may-legal-advice-contempt-proceedings-labour-dup (дата обращения: 04.12.2018 г.).

${ }^{3}$ Agreement on the withdrawal of the United Kingdom of Great Britain and Northern Ireland from the European Union and the European Atomic Energy Community, as endorsed by leaders at a special meeting of the European Council on 25 November 2018. Withdrawal Agreement and Political Declaration. URL: https://assets.publishing.service.gov.uk/ government/uploads/system/uploads/attachment_data/file/759019/25_November_Agreement_on_the_withdrawal_of_ the_United_Kingdom_of_Great_Britain_and_Northern_Ireland_from_the_European_Union_and_the_European_Atomi c_Energy_Community.pdf; Political Declaration Setting out the Framework for the Future Re-ationship Between the European Union and the United Kingdom. URL: https://assets.publishing.service.gov.uk/government/uploads/system/ uploads/attachment_data/file/759021/25_November_Political_Declaration_setting_out_the_framework_for_the_future_ relationship_between_the_European_Union_and_the_United_Kingdom__.pdf (дата обращения: 04.12.2018 г.). 
кулами парламента правительству удавалось проводить свою линию по лезвию бритвы. Дело в том, что брекзитёры-тори из парламентской фракции, отказались от выражения недоверия Терезе Мэй как лидеру партии, избрав тактику обструкции в парламенте. Они терпели поражение, поскольку несколько «перебежчиков»-лейбористов голосовали солидарно с правительством, вопреки «генеральной линии» своей партии.

Однако в первый же день дебатов 4 декабря правительство потерпело три унизительных поражения. Напомним, у консерваторов 318 мест в парламенте, у ДЮП - 10 мест (партия, отметим, после досрочных выборов 2017 г. заключила с консерваторами соглашение о поддержке в парламенте), то есть в общей сложности 328 мест, а большинство составляет 320 голосов ${ }^{1}$.

Началось оно с голосования по предложению правительства передать в Комитет по привилегиям вопрос о том, проявило ли оно неуважение к парламенту, отказываясь опубликовать полный текст доклада Генерального прокурора Дж. Кокса о юридической оценке последствий соглашения с ЕС (вместо краткого заключения).

Итог голосования: 311:307

Соответственно, второе голосование касалось порицания правительству за неуважение к парламенту за отказ опубликовать полный текст доклада. Депутаты, решая судьбу Британии, хотели бы вынести «информированное суждение», для чего им необходимо было видеть его полный текст. Дело в том, что Кокс заявил: Британия вынуждена будет соблюдать таможенные правила ЕС «неопределённое время», если переговоры о торговом соглашении с ЕС провалятся (Британия не будет обладать правом одностороннего выхода из соглашения), хотя это и противоречит интересам обеих сторон - таков «просчитанный риск» ${ }^{2}$. Кокс отказался обнародовать свой доклад, поскольку это противоречило бы «национальным интересам» ${ }^{3}$.

Предложение о неуважении правительства к парламенту внесли ДЮП, лейбористы, ШНП, либеральные демократы, Плайд Камри (Уэльс) и «зелёные». Неуважение к парламенту считается серьёзным нарушением, поскольку не позволяет депутатам исполнять свои обязанности. Вероятно, виновные члены правительства могут получить от порицания до приостановления их депутатских полномочий (члены правительства имеют депутатские мандаты).

Итог голосования: 311:293.

Правительство обязали опубликовать полный текст доклада Генерального прокурора Кокса, что и было сделано. Постановление парламента представляет огромную конституционную и политическую значимость, поскольку меняет соотношение полномочий между исполнительной и законодательной властью.

Третье предложение заключалось в том, чтобы Палата общин получила право определять дальнейшие действия, если депутаты отвергнут Соглашение Британии с $\mathrm{EC}^{4}$.

Итог голосования: 321:299.

Резолюция парламента позволяет депутатам вносить поправки в Соглашение с Евро-

\footnotetext{
${ }^{1}$ В работе парламента не принимают участие 7 депутатов от партии Шинн Фейн, не имеют право голосовать спикер и три его заместителя.

${ }^{2}$ Brexit backstop plan is calculated risk - Geoffrey Cox. URL: https://www.bbc.com/news/uk-politics-46419790 (дата обращения: 04.12.2018 г.). Полный текст опубликован 5 декабря. 5 December EU Exit: Attorney General's legal advice to Cabinet on the Withdrawal Agreement and the Protocol on Ireland/Northern Ireland. URL: https://assets.publi shing.service.gov.uk/government/uploads/system/uploads/attachment_data/file/761852/05_December-_EU_Exit_Attor ney_General_s_legal_advice_to_Cabinet_on_the_Withdrawal_Agreement_and_the_Protocol_on_Ireland-Northern_Ire land.pdf (дата обращения: 4 декабря 2018 г.).

${ }^{3}$ BREXIT LIVE: May faces FRESH DISASTER as Government accused of committing CONTEMPT. URL: https://w ww.express.co.uk/news/politics/1053507/brexit-live-theresa-may-legal-advice-contempt-proceedings-labour-dup.

${ }^{4}$ Theresa May suffers three Brexit defeats in Commons. URL: https://www.bbc.com/news/uk-politics-46446694.
} 
пейским союзом. Тем самым решение может снять угрозу премьер-министра Т. Мэй, что выбор предстоит между «её сделкой» и брекзитом без сделки.

Данную поправку внёс бывший Генеральный прокурор Британии Д. Грив, активный бремейнер. Однако ярый брекзитёр и противник Т. Мэй, Дж. Рис-Могг на этот раз поддержал правительство, поскольку опасался, что поправка снимет вероятность выхода без сделки, а выход без сделки для брекзитёров предпочтительнее Соглашения с ЕС, которое заключила Т. Мэй. Более того, он даже уговорил нескольких лейбористов голосовать солидарно с консервативным правительством.

Таким образом, не правительство предложит парламенту дальнейшие действия, если парламент не одобрит Соглашение с Евросоюзом, а парламент может указать правительству, как действовать дальше. Однако резолюция парламента не имеет статус закона, в то время как Раздел 13.1 (b) Закона о выходе из EC (Section 13.1 (b) of the European Union (Withdrawal) Act 2018) гласит, что Соглашение о выходе и рамочное соглашение о будущих отношениях «одобрены» резолюцией Палаты общин по предложению (motion) правительства (а оно «нейтрально», то есть не подлежит изменению). Соответственно, поправка Д. Грива не обладает обязательной юридической силой, что вызвало вздох облегчения у брекзитёров. В противном случае (исключения сценария выхода из ЕС без сделки) они могут проголосовать за Соглашение с ЕС, чтобы предотвратить отказ парламента от брекзита в принципе.

Снова встаёт вопрос о перераспределении полномочий между исполнительной и законодательной ветвями власти, хотя в данном случае исполнительная власть будет решать, как действовать дальше ${ }^{1}$. Всё же исход голосования окажет влияние на общественное мнение, игнорировать которое правительство будет не в состоянии.

\section{«Разброд и шатание»}

Голосование по Соглашению с ЕС должно было состояться 11 декабря, и в парламенте нет большинства ни по одному из вариантов брекзита ${ }^{2}$, как и по отказу от него или новому референдуму. Т. Мэй отложила голосование до третьей недели января 2019 г., осознав, что «её сделка» провалится, и направилась в Амстердам и Берлин на встречу с А. Меркель и М. Рютте. Этот шаг вызвал возмущение парламента и даже однопартийцев. Письма с выражением недоверия Т. Мэй направили более 48 депутатов-тори, что автоматически привело к объявлению вотума доверия лидеру партии. Вотум доверия Т. Мэй выиграла (200:117), но на результатах сказалось её обещание уйти с поста главы партии до «следующих всеобщих выборов». Однако Т. Мэй имеет в виду очередные выборы 2022 г. Между тем новые досрочные выборы не исключены. Здесь возникает вопрос, останется ли она лидером партии, если досрочные выборы состоятся до истечения года со дня вотума доверия (повторный вотум доверия может состояться лишь через год).

Проводя досрочные выборы в 2017 г., Т. Мэй стремилась избежать именно такого разброда, но Консервативная партия утратила тогда большинство, и даже соглашение с ДЮП ныне под вопросом. ДЮП намерена отказать правительству в поддержке, если парламент проголосует за Соглашение с ЕС (позиция правительства), и поддержит его, если парламент проголосует против сделки (против правительства).

Не прибавила авторитета премьер-министру и неудачная попытка Т Мэй всё же до-

\footnotetext{
${ }^{1}$ NO DEAL DEAD: MPs vote to APPROVE Dominic Grieve's SHOCK amendment to Withdrawal Act. URL: https:// www.express.co.uk/news/politics/1054281/brexit-news-no-deal-brexit-vote-dominic-grieve-theresa-may-eu-deal (дата обращения: 04.12.2018 г.).

${ }^{2}$ Норвежский вариант, например, предполагает свободу передвижения рабочей силы, то есть въезд мобильных граждан ЕС в Британию, против чего собственно и проголосовало большинство на референдуме 2016 г.
} 
биться уступок от Европейского союза на его саммите 13-14 декабря. ЕС отказался пересматривать соглашение. Он оговорил лишь готовность возможно быстрее начать и закончить переговоры по будущим отношениям с Британией. Цель - избежать введения «последней гарантии» (backstop), т.е. сохранения членства Северной Ирландии в Таможенном союзе ЕС после переходного периода, если иное решение не будет найдено ${ }^{1}$.

Таким образом, Мэй не получила уступки от Евросоюза. Выиграв вотум доверия, она не повысила свой моральный авторитет и не продвинулась в привлечении большинства в парламенте по предстоящему голосованию по соглашению.

Между тем четыре оппозиционные партии (ШНП, ПЛД, «Зелёные», Плайд Камри) подталкивают лидера ведущей оппозиционной партии - Лейбористской объявить вотум доверия правительству, пока правящую партию консерваторов раздирают распри. Однако цели оппозиционных партий не совпадают. Цель Дж. Корбина - досрочные выборы: обе партии в опроcax по-прежнему идут «ноздря в ноздрю» ${ }^{2}$ : хаос в политических кругах не отразился на рейтингах ведущих партий. Соответственно, объявить вотум доверия правительству, по мнению Дж. Корбина, следует после провала в парламенте «сделки» Т. Мэй с ЕС (тогда часть консерваторов может проголосовать за недоверие правительству вместе с оппозицией). Цель тех, кто торопится с вотумом доверия правительству, - второй референдум по отношениям с ЕС. К ним примыкают группа консерваторов и депутаты от крыла умеренных бремейнеров-лейбористов (Чука Уманна, Маргарет Беккет), отнюдь не союзников Корбина. Их тактика заключается в том, что до голосования по «сделке» именно правительство выиграет вотум доверия. Соответственно, досрочных выборов не будет, а Лейбористкой партии придётся поддержать практически последний вариант выхода из тупика - второй референдум по отношениям с Европейским союзом. Бремейнеры рассчитывают его выиграть, добившись включения в бюллетень формулировки «остаться в ЕС» как одного из вариантов ответа.

Действительно, опрос Yougov 3-4 декабря показал, что относительное большинство британцев считают неверным решение выйти из Евросоюза (49:38), но лишь 23\% против 46\% респондентов поддерживают Соглашение с ЕС. К опросам общественного мнения следует подходить с осторожностью - иные опросы свидетельствуют: за выход из ЕС респонденты высказались в соотношении 45 к 44, хотя мнение относительно Соглашения с ЕС примерно такое же $-26: 41^{3}$.

Не только ведущие и бывшие крупные политические деятели из разных политических лагерей (Т. Блэр, Дж. Мэйджор) высказываются за второй референдум, но и авторитетные СМИ - The Economist, The Telegraph, The Times ${ }^{4}$ стали склоняться к идее второго референдума.

\footnotetext{
${ }^{1}$ Special meeting of the European Council (Art. 50) (13 December 2018) - Conclusions. URL: http://data.consilium. europa.eu/doc/document/XT-20022-2018-INIT/en/pdf (дата обращения 14.12.2018).

${ }_{2}^{2}$ UK Polling Report. 16.12.2018. URL: http://ukpollingreport.co.uk/ (дата обращения 21.12.2018).

${ }^{3}$ YouGov / The Times Survey Results. URL: https://d25d2506sfb94s.cloudfront.net/cumulus_uploads/document/yu4cn evthm/TheTimes_181204_VI_Trackers_bpc_w.pdf; «LISTEN TO THE PEOPLE!» Rees-Mogg says «establishment DOESN'T know best»- new BREXIT POLL. URL: https://www.express.co.uk/news/politics/1053817/brexit-newstheresa-may-brexit-deal-jacob-rees-mogg (дата обращения 04.12.2018).

${ }^{4}$ John Major: case for second Brexit referendum is credible. URL: https://www.theguardian.com/politics/2016/nov/25/ brexit-sir-john-major-says-perfectly-credible-case-for-second-referendum (дата обращения 15.12.2018); Timothy N. Theresa May lives to fight another day, but there is no doubt her Brexit deal is dead. URL: https://premium.telegraph. co.uk/newsletter/article1/theresa-may-lives-to-fight-another-day-but-there-is-no-doubt-her-brexit-deal-is-dead/?WT.mc _id=e_DM898248\&WT.tsrc=email\&etype=Edi_Edi_New_nReg_VarA\&utm_source=email\&utm_medium=Edi_Edi_N ew_nReg_VarA_2018_12_13\&utm_campaign=-DM8̄98248 (дата обращения: 15.12.2018); The real lesson from Theresa May's bruising week. URL: https://www.economist.com/leaders/2018/12/13/the-real-lesson-from-theresa-maysbruising-week?cid1=cust/ednew/n/bl/n/2018/12/13n/owned/n/n/nwl/n/n/e/176773/n (дата обращения: 14.12.2018).
} 
Более того, идея вызревает и в коридорах властиㄹ : стратегия состоит в том, чтобы индикативным голосованием по различным вариантам пошагово исключать все, кроме одного - референдума.

Второй референдум вызывает неприятие брекзитёров, а также опасения, что Шотландия в связи с новым референдумом по отношениям Британии с ЕС захочет провести свой новый референдум о независимости от Британии.

Премьер-министр, осадив членов своего Кабинета, назначила голосование по Соглашению с Евросоюзом на неделю 14-21 января 2019 г. - последняя возможность выйти «со сделкой»: позже Британии и странам - членам ЕС не хватит времени ратифицировать Соглашение Британии с ЕС, закончить всю процедуру, и, таким образом, страна выйдет из Евросоюза «без сделки». Тем самым Т. Мэй стремится поставить парламент перед выбором, который давно обозначила: «ее сделка» или выход «без сделки» («it’s my deal or no deal»). Лейбористы, соответственно, лишаются возможности объявить вотум доверия правительству после голосования, чтобы попытаться провести переговоры с Брюсселем на новых основаниях.

К тому же, новый референдум по отношениям с Европейским союзом вряд ли успеют провести до даты выхода Британии из Евросоюза: назначенные на май выборы в Европарламент (ЕП) пройдут уже без Соединённого Королевства, а его квоту на места в ЕП уже перераспределили между странами-членами.

Лондон всё же начал готовиться к выходу без сделки, хотя ранее не желал принимать меры на случай такого исхода, опасаясь вдохновить брекзитёров.

Между тем в Брюсселе заранее стали принимать меры в случае выхода Британии «без сделки», поскольку не намерены были возобновлять переговоры, а также за закрытыми дверями готовятся к ратификации соглашения Европарламентом².

Неудивительно, что в условиях крайнего обострения политической ситуации для правительства министр обороны Г. Уильямсон заявил о возвращении страны к стратегии противодействия России времён холодной войны ${ }^{3}$, активизации министерства в Арктике и на Украине. Не исключены и новые провокации против РФ. Борьба с «внешней угрозой» остаётся прибежищем ослабленных политических сил для «сплочения нации».

\section{Выводы}

1. Неуважение к парламенту считается в Британии серьёзным нарушением. Вероятно, что виновные члены правительства могут получить от порицания до приостановления их депутатских полномочий, что ослабит положение правительства Т. Мэй, усиливая позиции брекзитёеров.

2. Декабрьские резолюции парламента представляют огромную конституционную и политическую значимость, поскольку меняют соотношение полномочий между исполнительной и законодательной властью.

3. Отложив голосование по Соглашению с Европейским союзом, правительство не укрепило свои позиции, как не укрепила своё положение и авторитет Т. Мэй, даже выиграв вотум доверия парламентской фракции консерваторов, но не добившись уступок от Брюсселя

\footnotetext{
${ }^{1}$ The Cabinet «STRATEGY» that could lead to a second referendum REVEALED- «NO OTHER OPTION!». URL: https://www.express.co.uk/news/politics/1059412/brexit-news-latest-theresa-may-deal-second-referendum-vote-jojohnson (дата обращения 15.12.2018).

2 BREXIT BOMBSHELL: EU leaders planning NO DEAL summit as fears grow for May's deal. URL: https://www. express.co.uk/news/uk/1051496/Brexit-news-UK-EU-Theresa-May-withdrawal-deal-vote-Parliament-no-deal-latest. (дата обращения: 28.11.2018 г.).

3 U.K. Adopts Cold War Strategy to Tackle Threat From Russia. URL: https://www.bloomberg.com/news/articles/ 2018-12-18/u-k-adopts-cold-war-strategy-to-tackle-threat-from-russia (дата обращения 21.12.2018).
} Научно-аналитический вестник ИЕ РАН, 2018, №6 
на саммите ЕС 13-14 декабря.

4. Евросоюз отказался вносить изменения в Соглашение с Британией, что ослабляет позиции Лондона.

5. Постановление Суда ЕС о возможности отзыва уведомления о намерении Британии выйти из Евросоюза оказывает моральную поддержку бремейнерам, но правительство Т. Мэй на подобный шаг не пойдёт.

6. И политические круги и общественное мнение по-прежнему расколоты по «европейскому вопросу», Соглашение с ЕС не пользуется поддержкой населения.

7. Т. Мэй пытается исключить повторный референдум как инструмент выхода из политического тупика, что, как справедливо указывает правительство, может вызвать общественные беспорядки.

8. Исход самого брекзита остаётся открытым.

9. В условиях «войны всех против всех» в британском истеблишменте не исключены новые антироссийские действия правительства Т. Мэй.

\section{Список литературы}

Ананьева Е.В. Основные события и тенденции политического сезона 2017/2018 гг. в Британии // «Правительство меньшинства Терезы Мэй - год у власти», [сб. статей] / отв. ред. Ананьева Е.В. ДИЕ РАН №356, 2018/ С. 23-33. URL: http://www.instituteofeurope.ru/images/uploads/doklad/356.pdf.

Ананьева Е.В. Тереза Мэй между Брекзитом и Брино. Аналитическая записка №6(102), 2018. Институт Европы PAH.

URL: http://www.instituteofeurope.ru/images/uploads/analitika/2018/an102.pdf.

Бабынина Л.О. Великобритания и ЕС: перспективы сотрудничества. Современная Европа. 2018. №4. C. 57-67.

\section{References}

Ananieva E.V. Osnovnye sobytiya i tendencii politicheskogo sezona 2017/2018 gg. V Britanii // «Pravitel'stvo men'shinstva Terezy Mehj - god u vlasti», [sb. statej] / otv. red. Ananieva E.V. DIE RAN №356, 2018. S.23-33. URL: http://www.instituteofeurope.ru/images/uploads/doklad/356.pdf.

Ananieva E.V. Tereza Mehj mezhdu Brekzitom i Brino. Analiticheskaya zapiska №6(102), 2018. Institut Evropy RAN. URL: http://www.instituteofeurope.ru/images/uploads/analitika/2018/an102.pdf/

Babynina L.O. Velikobritanija i ES: perspektivy sotrudnichestva. Sovremennaja Evropa. 2018. №4. S. 57-67.

Boris Johnson's popularity has plummeted among Conservative and Leave voters. URL: https://yougov.co.uk/news/2018/10/16/boris-johnsons-popularity-has-plummeted-among-cons/

Bush S. Are these the last days of Theresa May? URL: https://www.newstatesman.com/ politics/elections/2018/10/are-these-last-days-theresa-may. 22.10.2018/

UK Polling Report. 28.11.2018; 16.12.2018. URL: http://ukpollingreport.co.uk/

Who would the public prefer to be Prime Minister: Jeremy Corbyn or Boris Johnson? URL: https://yougov.co.uk/news/2018/09/26/who-would-public-prefer-be-prime-minister-jeremy-c/

Yougov.co.uk. Top Issues Tracker. URL: http://d25d2506sfb94s.cloudfront.net/cumulus_ uploads/document/edqs7bhjxy/YG\%20Trackers\%20-\%20Top\%20Issues_W.pdf.

3 things we've learned about attitudes to the Conservative leadership. URL: https://yougov.co.uk/news/2018/10/02/3-things-weve-learned-about-attitudes-conservative/ 


\section{Brexit: A Second Referendum?}

Author. Elena Ananieva, Candidate of Sciences (Philosophy), Head of Centre for UK Studies, Institute of Europe, Russian Academy of Sciences. Address: 11-3, Mokhovaya str., Moscow, Russia, 125009. E-mail: e-ananieva@yandex.ru.

Abstract. Having acknowledged that the EU UK Withdrawal Agreement had no chances to pass through parliament Th. May postponed the «meaningful vote» until the last minute (January 14-21, 2019). The vote of confidence won by the Tory leader did not boost her authority. Even members of her own government are considering various plans for future moves on Brexit. Meanwhile opinion polls show even ratings of the two main parties and no majority on ways forward concerning relations with the EU. Is there a chance for a new referendum as a breakthrough from the political deadlock?

Key words: UK, European Union, Brexit, public opinion polls, EU UK Withdrawal Agreement, ECJ, Westminster, Th. May.

DOI: http://dx.doi.org/10.15211/vestnikieran6201810 